\title{
Emotion Detection by Analyzing Voice Signal Using Wavelet
}

\author{
Faishal Badsha1, Rafiqul Islam² \\ ${ }^{1}$ Department of Mathematics and Statistics, Bangladesh University of Business and Technology (BUBT), Dhaka, Bangladesh \\ ${ }^{2}$ Mathematics Discipline, Science, Engineering and Technology School, Khulna University, Khulna, Bangladesh \\ Email: badsha@bubt.edu.bd, mrislam_66@yahoo.com
}

How to cite this paper: Badsha, F. and Islam, R. (2020) Emotion Detection by Analyzing Voice Signal Using Wavelet. American Journal of Computational Mathematics, 10, 485-502.

https://doi.org/10.4236/ajcm.2020.104028

Received: September 30, 2020

Accepted: November 28, 2020

Published: December 2, 2020

Copyright $\odot 2020$ by author(s) and Scientific Research Publishing Inc. This work is licensed under the Creative Commons Attribution International License (CC BY 4.0).

http://creativecommons.org/licenses/by/4.0/

\begin{abstract}
Emotion is such a unique power of human trial that plays a vital role in distinguishing human civilization from others. Voice is one of the most important media of expressing emotion. We can identify many types of emotions by talking or listening to voices. This is what we know as a voice signal. Just as the way people talk is different, so is the way they express emotions. By looking or hearing a person's way of speaking, we can easily guess his/her personality and instantaneous emotions. People's emotion and feelings are expressed in different ways. It is through the expression of emotions and feelings that people fully express his thoughts. Happiness, sadness, and anger are the main medium of expression way of different human emotions. To express these emotions, people use body postures, facial expressions and vocalizations. Though people use a variety of means to express emotions and feelings, the easiest and most complete way to express emotion and feelings is voice signal. The subject of our study is whether we can identify the right human emotion by examining the human voice signal. By analyzing the voice signal through wavelet, we have tried to show whether the mean frequency, maximum frequency and $L_{p}$ values conform to a pattern according to its different sensory types. Moreover, the technique applied here is to develop a concept using MATLAB programming, which will compare the mean frequency, maximum frequency and $L_{p}$ norm to find relation and detect emotion by analyzing different voices.
\end{abstract}

\section{Keywords}

MATLAB Programming, Wavelet, Haar Decomposition, Voice Signal, Mean Frequency, Maximum Frequency, $L_{p}$ Norm

\section{Introduction}

With the advancement of science, we generally became dependent on machines. 
Feature as machine learning, robotics, data science etc. have made our life easier and more enjoyable day by day. Although it is not possible to give emotion and feelings to a machine, we can often accurately identify the expression of emotions and feelings of a person by machine, analyzing the voice signal. We analyze voice signal by signal processing. When we want to express an emotion or feeling through our throat or through speech or through spoken or unspoken words, it simply takes the form of a basic signal in the form of sine and cosine [1]. These signals vary according to the type of person and person's voice. By processing these voice signals, we can get an idea of the individual's characteristics, identify him by his precious work and identify his various emotion. In previous these signals were processed with Fourier series and Fourier transform but there are some problems as Fourier series is not well time localized [2]. We use Haar wavelet to process our voice signal because wavelet is well time localized [3]. Although voice identification and classification began in early 1960's, it is now a very rich research field like image processing [4]. This enrichment of research is due to some of the characteristics that determine the character of a voice signal, such as loudness, amplitude, mean frequency, maximum frequency, $L_{p}$ norm, standard deviation etc. which differ from person to person. We have calculated the unique feature of signal by analyzing the voice signals, which are composed of five-level decomposition through Haar wavelet [5]. Emotion detection, one of the fields of speech classification, is a technique of extracting the speech characteristic information from people voice, and then is analyzed through machine and identifies the uniqueness of speech. Speech classification is an interconnected field of many others fields like image processing, robotics, artificial intelligence, machine learning, etc., currently a lot of work being done in machine learning with voice classification, voice identification and emotion detection, which has enriched our robotics much more. A large part of robotics today depend on speech command through which our daily electronic turns away from its button and switch. By adding speech classification to machine learning, we can look at a person's speech record and store the emotion of his speech as data to estimate his next field of emotion. With the addition of the voice detection feature to the CCTV camera, we can easily identify the culprit through emotion detection by hearing the voice without looking at the face. Emotion detection plays an important role for people with physical and mental disabilities who communicate mainly through machines. Therefore, emotion detection or voice classification has not only made our daily lives easier, it has become a more important part of our life. There are many ways of classifying voice for emotion detection; wavelet is one of the best tools among them [6].

\section{Methodology}

\subsection{Wavelet}

The wavelet means small waves and in brief, a wavelet is an oscillation that decays quickly. Equivalent mathematical conditions for wavelet are: 


$$
\begin{aligned}
& \text { i) } \int_{R}|\psi(x)|^{2} \mathrm{~d} x<\infty \\
& \text { ii) } \int_{R} \psi(x) \mathrm{d} x=0 \\
& \text { iii) } \int_{R} \frac{|\hat{\psi}(\omega)|^{2}}{|\omega|} \mathrm{d} \omega<\infty
\end{aligned}
$$

where $\hat{\psi}(\omega)$ is the Fourier Transform of $\psi(x)$ [7].

\subsection{Haar Wavelet}

The Hungarian mathematician Alfred Haar first introduced the Haar function in 1909 in his Ph.D. thesis.

A function defined on the real line $\mathfrak{R}$ as

$$
\psi(t)=\left\{\begin{array}{l}
1 \text { for } t \in\left[0, \frac{1}{2}\right) \\
-1 \text { for } t \in\left[\frac{1}{2}, 1\right) \\
0 \text { otherwise }
\end{array}\right.
$$

Is known as the Haar function [7].

The Haar function $\psi(t)$ is the simplest example of a Haar Wavelet. The Haar function $\psi(t)$ is a wavelet because it satisfies all the conditions of wavelet. This fundamental example has all the major features of the general wavelet theory. Haar wavelet is discontinuous at $t=0, \frac{1}{2}, 1$ and it is very well localized in the time domain.

The Fourier transform of $\psi(t)$ is given by

$$
\begin{gathered}
\hat{\psi}(\omega)=i \exp \left(-\frac{i \omega}{2}\right) \frac{\sin ^{2}\left(\frac{\omega}{4}\right)}{\frac{\omega}{4}} \\
\therefore \operatorname{Re}\{\hat{\psi}(\omega)\}=\sin \left(\frac{\omega}{2}\right) \frac{\sin ^{2}\left(\frac{\omega}{4}\right)}{\frac{\omega}{4}} .
\end{gathered}
$$

\subsection{Signal}

A signal is defined as a function $f(x)$, which has a series representation

$$
f(x)=\sum_{n=0}^{\infty} a_{n} x^{n}
$$

Then all information about the function $f$ is stored in the coefficients $\left\{a_{n}\right\}_{n=0}^{\infty}$ [8].

\subsection{Wavelets and Signal Processing}

The mathematical theory for wavelets deals for a great part with ways of obtain- 
ing series expansions of the type $f(x)=\sum_{j \in Z} \sum_{k \in Z} d_{j, k} \psi_{j, k}(x)$ for certain functions $f$. Very often, the relevant functions $f$ describe the time dependence of certain signals, i.e. the vibrations in a mechanical system or the current in an electric circuit. We now shortly describe a property of wavelets, which distinguish representations of the type $f(x)=\sum_{j \in Z} \sum_{k \in Z} d_{j, k} \psi_{j, k}(x)$ from the general representations $f(x)=\sum_{n=0}^{\infty} a_{n} f_{n}(x)[8][9]$.

\subsection{Frequency and Maximum Frequency}

Frequency is the number of occurrences of a repeating event per unit time. In physics frequency is the number of waves that pass a fixed point in unit time; also, the number of cycle or vibration during one unit of time by a body in periodic motion. A body in periodic motion is said to have undergone one cycle of one vibration after passing through a series of events of positions and returning to its original state. If the period, or time interval, required to complete one cycle of vibration is $1 / 2$ second, the frequency is two per second [10]. The symbol most often used for frequency are $f$ and the Greek letters $\vartheta$ (nu) and omega $\omega$. In general, the frequency is the reciprocal of the period, or time interval. If $T$ is the time period to complete one cycle then the frequency $f$ can be written as

$$
f=\frac{1}{T}
$$

When the number of cycle in a unit period is maximum then the frequency is maximum.

\subsection{Mean Frequency}

The mean frequency of a spectrum is calculated as the sum of the product of the spectrogram intensity (in $\mathrm{dB}$ ) and the frequency, divided by the total sum of spectrogram intensity [10]. If $n$ is the number of frequency bins in the spectrum, $f_{i}$ is the frequency of spectrum at bin $i$ of $n$ and $I_{i}$ is the intensity (in $\mathrm{dB}$ ) of spectrum at bin $i$ of $n$ then the mean frequency $f_{\text {mean }}$ can be written as follows,

$$
f_{\text {mean }}=\frac{\sum_{i=0}^{i=n} I_{i} f_{i}}{\sum_{i=0}^{i=n} I_{i}}
$$

\section{7. $L_{p}$ Norm}

For finite $p, L_{p}$ Norm in $c[a, b]$ is defined as

$$
\|f\|_{p}=\left[\int_{a}^{b}|f(x)|^{p} \mathrm{~d} x\right]^{\frac{1}{p}} ; 1 \leq p<\infty
$$

For discrete function it can be defined as

$$
\|f\|_{p}=\left[\sum_{i=1}^{n}\left|f\left(x_{i}\right)\right|^{p}\right]^{\frac{1}{p}}
$$


where $\left\{x_{i}\right\}$ are the components of $f[11]$.

If we put $p=1$ in the above equation then $\|f\|_{1}$ is called $L_{1}$ Norm.

If we put $p=2$ in the above equation then $\|f\|_{2}$ is called $L_{2}$ Norm.

\section{Experimental Sample}

Here we take twelve-voice sample from four people. We collected our voice sample in four different mood (joy, sorrow and angry) from each person.

\subsection{First Experimental Real Voice of First Person}

First experimental real voice of first person who speaks by a microphone and say, "can you please tell me what is going on" with joy in between 0 to 5 seconds

From statistical analysis of first experimental speech signal of first person, we see that, mean frequency of signal is $347 \mathrm{~Hz}$; maximum frequency of signal is $453 \mathrm{~Hz}, L_{1}$ Norm is 2263 and $L_{2}$ Norm is 23.35 .

\subsection{Second Experimental Real Voice of First Person}

Second experimental real voice of first person who speaks by a microphone and say, "can you please tell me what is going on" with sorrow in between 0 to 5 seconds.

From statistical analysis of second experimental speech signal of first person, we see that, mean frequency of signal is $323 \mathrm{~Hz}$, maximum frequency of signal is $428 \mathrm{~Hz}, L_{1}$ Norm is 2311 and $L_{2}$ Norm is 17.26 .

\subsection{Third Experimental Real Voice of First Person}

Third experimental real voice of first person who speaks by a microphone and say, "can you please tell me what is going on" with anger in between 0 to 5 seconds

From statistical analysis of third experimental speech signal of first person, we see that, mean frequency of signal is $376 \mathrm{~Hz}$, maximum frequency of signal is $508 \mathrm{~Hz}, L_{1}$ Norm is 2181 and $L_{2}$ Norm is 28.02 .

\subsection{First Experimental Real Voice of Second Person}

First experimental real voice of second person who speaks by a microphone and say, "can you please tell me what is going on" with joy in between 0 to 5 seconds.

From statistical analysis of first experimental speech signal of second person, we see that, mean frequency of signal is $366 \mathrm{~Hz}$, maximum frequency of signal is $481 \mathrm{~Hz}, L_{1}$ Norm is 2206 and $L_{2}$ Norm is 24.32 .

\subsection{Second Experimental Real Voice of Second Person}

Second experimental real voice of second person who speaks by a microphone and say, "can you please tell me what is going on" with sorrow in between 0 to 5 seconds.

From statistical analysis of second experimental speech signal of second per- 
son, we see that, mean frequency of signal is $313 \mathrm{~Hz}$, maximum frequency of signal is $423 \mathrm{~Hz}, L_{1}$ Norm is 2327 and $L_{2}$ Norm is 15.28 .

\subsection{Third Experimental Real Voice of Second Person}

Third experimental real voice of second person who speaks by a microphone and say, "can you please tell me what is going on" with anger in between 0 to 5 seconds.

From statistical analysis of third experimental speech signal of second person, we see that, mean frequency of signal is $380 \mathrm{~Hz}$, maximum frequency of signal is $497 \mathrm{~Hz}, L_{1}$ Norm is 2049 and $L_{1}$ Norm is 27.88 .

\subsection{First Experimental Real Voice of Third Person}

First experimental real voice of third person who speaks by a microphone and say, "can you please tell me what is going on" with joy in between 0 to 5 seconds.

From statistical analysis of first experimental speech signal of third person, we see that, mean frequency of signal is $372 \mathrm{~Hz}$, maximum frequency of signal is $456 \mathrm{~Hz}, L_{1}$ Norm is 2218 and $L_{2}$ Norm is 22.09 .

\subsection{Second Experimental Real Voice of Third Person}

Second experimental real voice of third person who speaks by a microphone and say, "can you please tell me what is going on" with sorrow in between 0 to 5 seconds.

From statistical analysis of second experimental speech signal of third person, we see that, mean frequency of signal is $319 \mathrm{~Hz}$, maximum frequency of signal is $433 \mathrm{~Hz}, L_{1}$ Norm is 2295 and $L_{2}$ Norm is 16.43 .

\subsection{Third Experimental Real Voice of Third Person}

Third experimental real voice of third person who speaks by a microphone and say, "can you please tell me what is going on" with anger in between 0 to 5 seconds.

From statistical analysis of third experimental speech signal of third person, we see that, mean frequency of signal is $396 \mathrm{~Hz}$, maximum frequency of signal is $514 \mathrm{~Hz}, L_{1}$ Norm is 2031 and $L_{2}$ Norm is 28.16 .

\subsection{First Experimental Real Voice of Forth Person}

First experimental real voice of forth person who speaks by a microphone and say, "can you please tell me what is going on" with joy in between 0 to 5 seconds.

From statistical analysis of first experimental speech signal of forth person, we see that, mean frequency of signal is $360 \mathrm{~Hz}$, maximum frequency of signal is $473 \mathrm{~Hz}, L_{1}$ Norm is 2188 and $L_{2}$ Norm is 24.07 ..

\subsection{Second Experimental Real Voice of Forth Person}

Second experimental real voice of forth person who speaks by a microphone and 
say, "can you please tell me what is going on" with sorrow in between 0 to 5 seconds.

From statistical analysis of second experimental speech signal of forth person, we see that, mean frequency of signal is $322 \mathrm{~Hz}$, maximum frequency of signal is $416 \mathrm{~Hz}, L_{1}$ Norm is 2235 and $L_{2}$ Norm is 17.28 .

\subsection{Third Experimental Real Voice of Forth Person}

Third experimental real voice of forth person who speaks by a microphone and say, "can you please tell me what is going on" with anger in between 0 to 5 seconds.

From statistical analysis of third experimental speech signal of forth person, we see that, mean frequency of signal is $402 \mathrm{~Hz}$, maximum frequency of signal is $518 \mathrm{~Hz}, L_{1}$ Norm is 2083 and $L_{2}$ Norm is 27.12 .

\section{Results and Discussions}

In the above experimental study, we tried to predict the approximate emotion by analyzing the four unique and basic feature (mean frequency, maximum frequency, $L_{1}$ norm and $L_{2}$ norm) of voice signal. In this purpose, we analyzed the voice signal by Haar wavelet (Shown in Figure 1). The signal frequency is nothing but sampling number. The number of sample of each of our signals is 40,000 . In our experiment, we have taken three voices in three different mood (Joy, sorrow, anger) from each of four people (Figures 2-13). We calculate mean frequency, maximum frequency, $L_{1}$ norm and $L_{2}$ norm for each voice (Tables 1-4). We can see from the table and chart (shown in Table 5 and Figure 14) the mean frequency vary from approximate $310 \mathrm{~Hz}$ to $400 \mathrm{~Hz}$ and the maximum frequency vary from approximate $410 \mathrm{~Hz}$ to $520 \mathrm{~Hz}$ for all the voice signals. Also the mean frequency vary from $340 \mathrm{~Hz}$ to $360 \mathrm{~Hz}$ approximately for joy, $310 \mathrm{~Hz}$ to $330 \mathrm{~Hz}$ approximately for sorrow, $365 \mathrm{~Hz}$ to $400 \mathrm{~Hz}$ approximately for anger and the maximum frequency vary from $450 \mathrm{~Hz}$ to $470 \mathrm{~Hz}$ approximately for joy, 410 $\mathrm{Hz}$ to $440 \mathrm{~Hz}$ approximately for sorrow, $480 \mathrm{~Hz}$ to $520 \mathrm{~Hz}$ approximately for anger. Again the $L_{1}$ Norm vary 2180 to 2250 approximately for joy, 2250 to 2330 approximately for sorrow and 2030 to 2190 approximately for anger where as $L_{2}$ Norm vary from 20 to 25 approximately for joy, 15 to 20 approximately for sorrow and 25 to 30 for anger (shown in Table 6, Figure 15 and Figure 16). Therefore, we can see anger voice gives highest number of frequency where the lowest frequency emitted from the voice of sorrow and joy ensures the moderate type of frequency. On the other hand, $L_{1}$ and $L_{2}$ norm behave in reverse in the case of high and low frequency. In case of angry voices, $L_{2}$ norm gives the highest value where as $L_{1}$ is lowest and for the sorrow, the phenomenon is completely different also. Therefore, the mean frequency of all the happy voices in between $340 \mathrm{~Hz}$ to $360 \mathrm{~Hz}$, the mean frequency of all the sorrow voices in between 310 $\mathrm{Hz}$ to $330 \mathrm{~Hz}$ and the mean frequency of all the angry voices in between $365 \mathrm{~Hz}$ to $400 \mathrm{~Hz}$. On the other hand the maximum frequency of all the happy voices in 
between $450 \mathrm{~Hz}$ to $470 \mathrm{~Hz}$, the maximum frequency of all the sorrow voices in between $410 \mathrm{~Hz}$ to $440 \mathrm{~Hz}$ and the maximum frequency of all angry voices in between $480 \mathrm{~Hz}$ to $520 \mathrm{~Hz}$. So in case of mean frequency and maximum frequency the frequency gradually increase from sorrow, joy to anger (shown in Table 5 and Figure 14). The $L_{1}$ norm of all the happy voices in between 2180 to 2250 , of all the sorrow voices in between 2250 to 2330 and of all the angry voices in between 2030 to 2190 . Where the $L_{2}$ norm of all the happy voices in between 20 to 25 , of all the sorrow voices in between 15 to 20 and of all the angry voices in between 25 to 30. It can be observed that $L_{1}$ norm and $L_{2}$ norm gradually increase and decrease respectively form sorrow, joy to angry (shown in Table 6, Figure 15 and Figure 16).

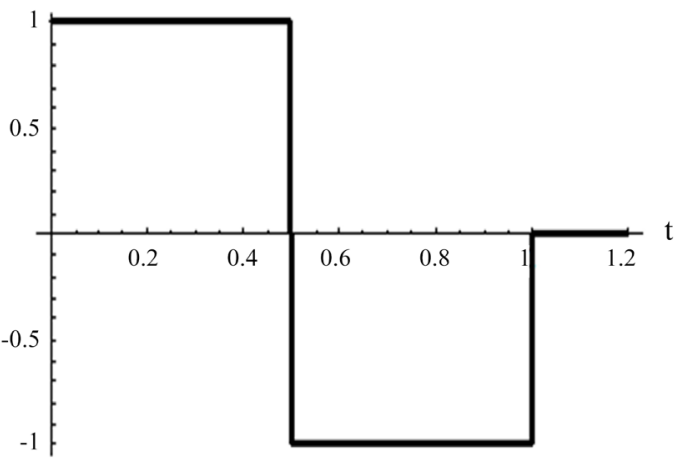

Figure 1. Haar wavelet.

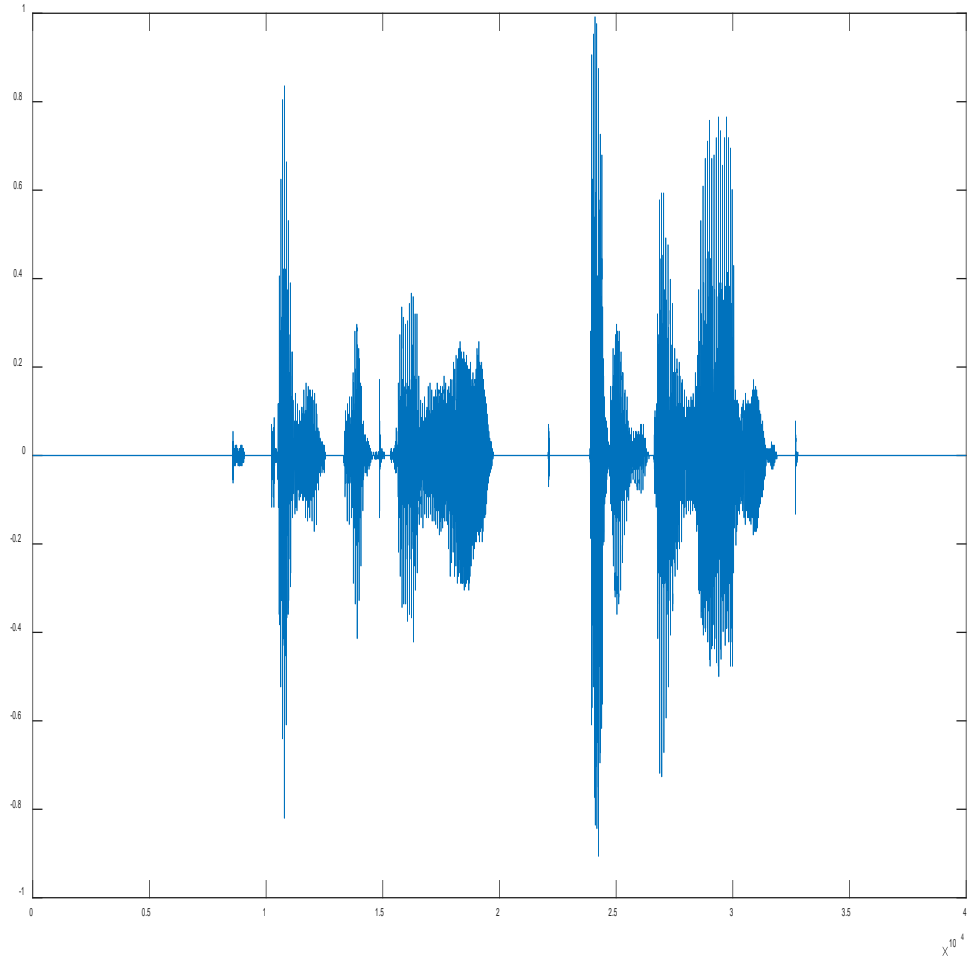

$\mathrm{X}$-axis $\rightarrow$ time, $\mathrm{Y}$-axis $\rightarrow$ amplitude

Figure 2. First experimental speech signal of first person. 


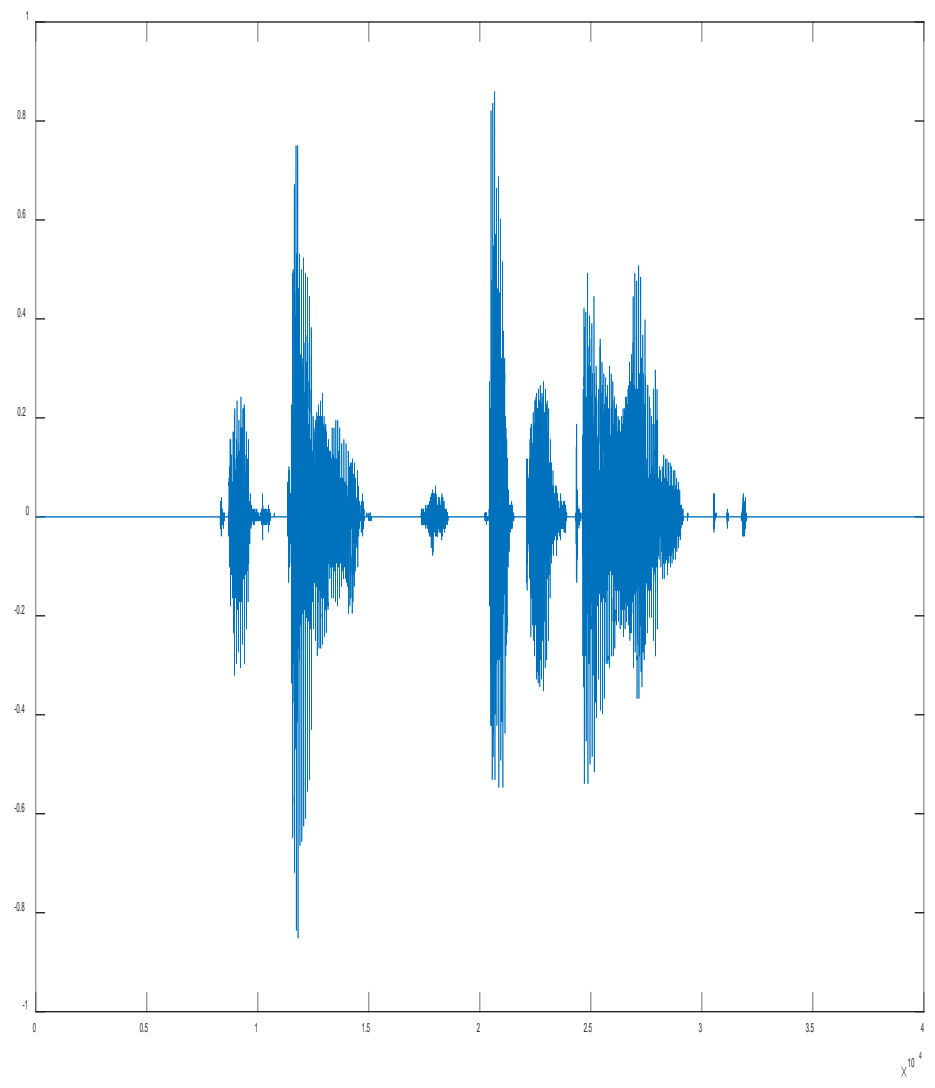

$\mathrm{X}$-axis $\rightarrow$ time, $\mathrm{Y}$-axis $\rightarrow$ amplitude

Figure 3. Second experimental speech signal of first person.

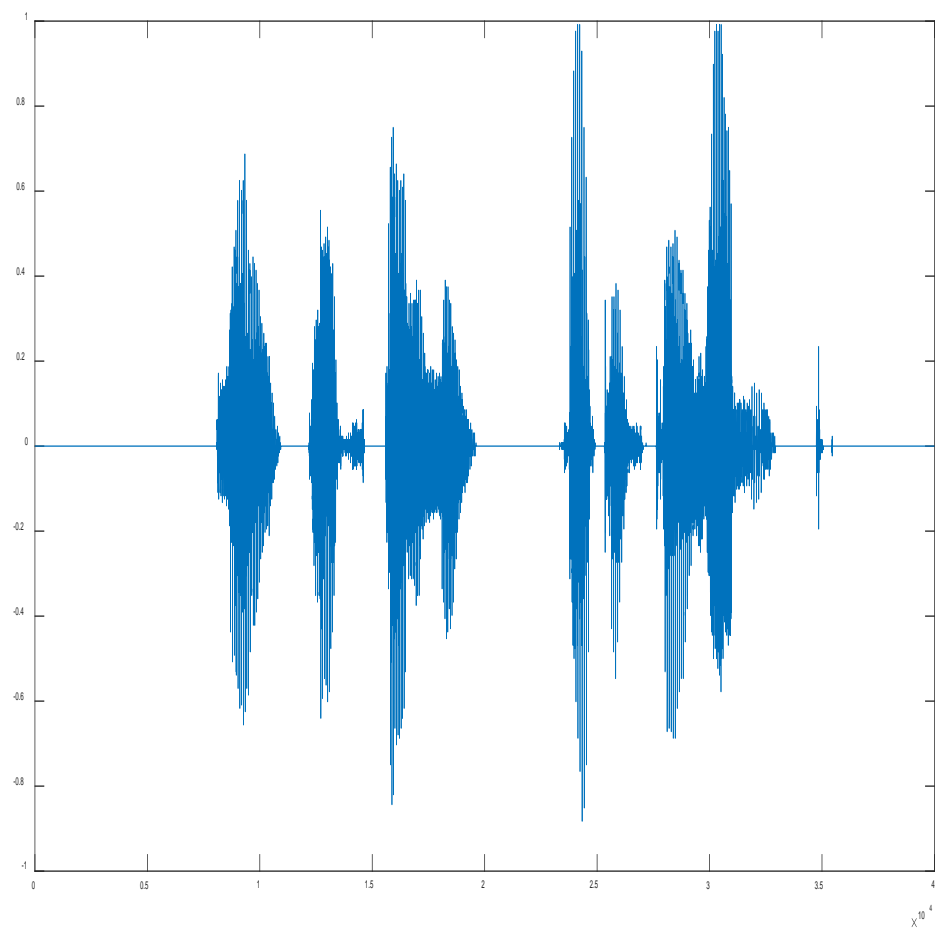

$\mathrm{X}$-axis $\rightarrow$ time, $\mathrm{Y}$-axis $\rightarrow$ amplitude

Figure 4. Third experimental speech signal of first person. 


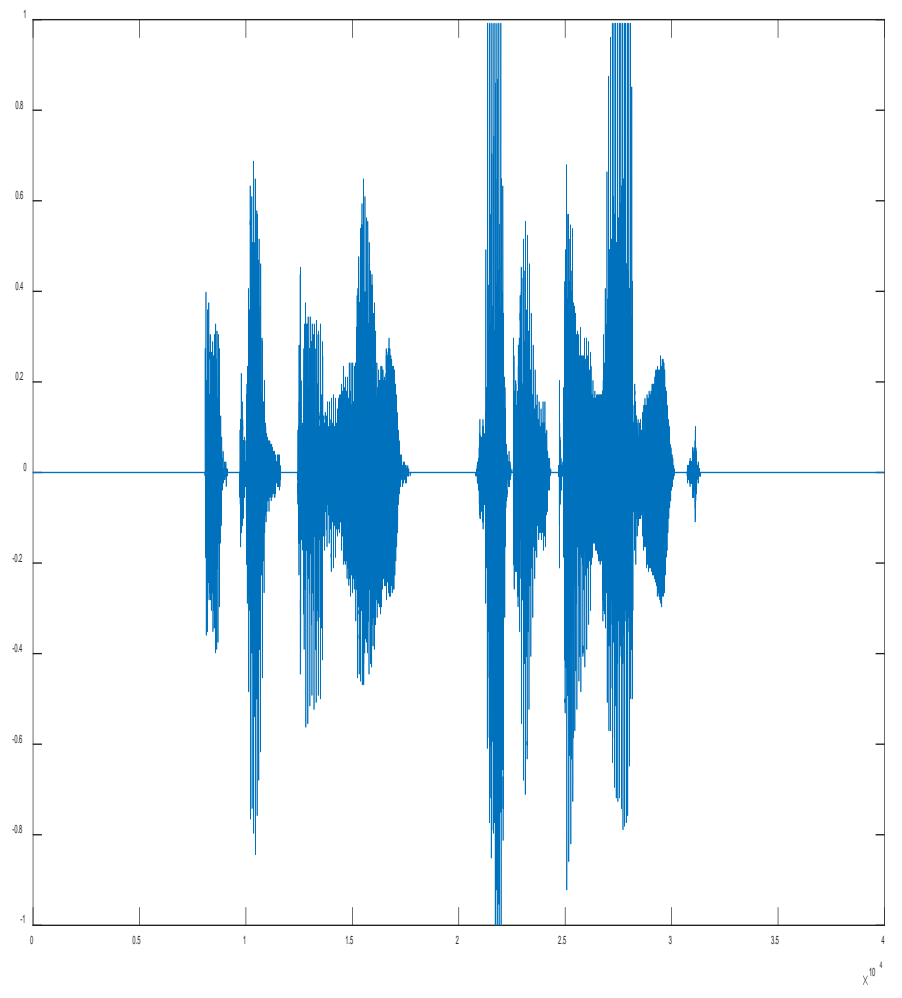

$\mathrm{X}$-axis $\rightarrow$ time, $\mathrm{Y}$-axis $\rightarrow$ amplitude

Figure 5. First experimental speech signal of second person.

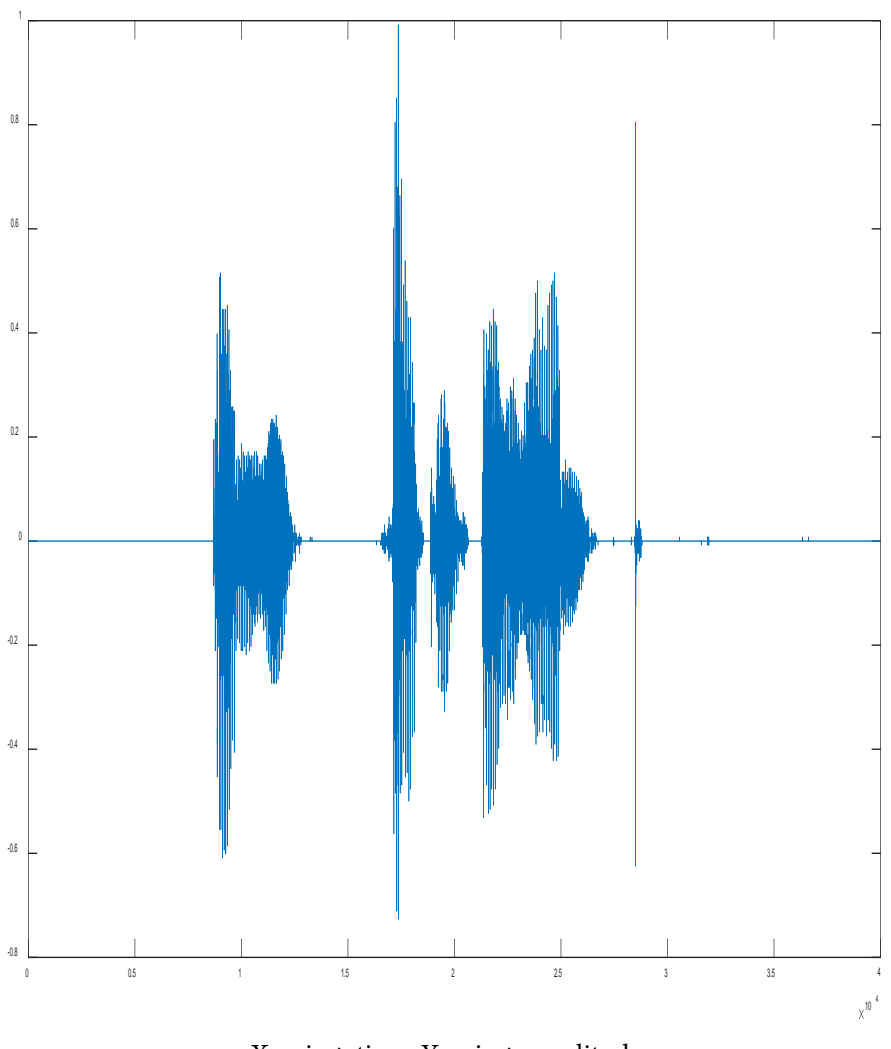

$\mathrm{X}$-axis $\rightarrow$ time, $\mathrm{Y}$-axis $\rightarrow$ amplitude

Figure 6. Second experimental speech signal of second person. 


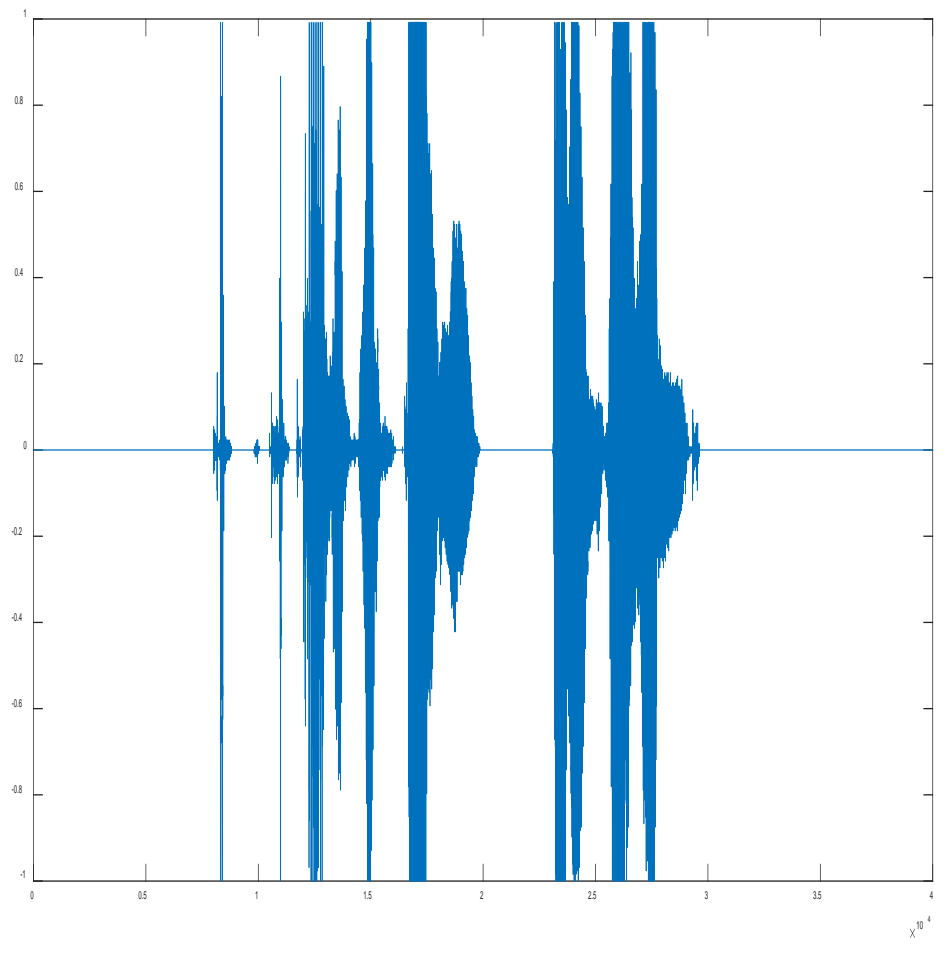

$\mathrm{X}$-axis $\rightarrow$ time, $\mathrm{Y}$-axis $\rightarrow$ amplitude

Figure 7. Third experimental speech signal of second person.

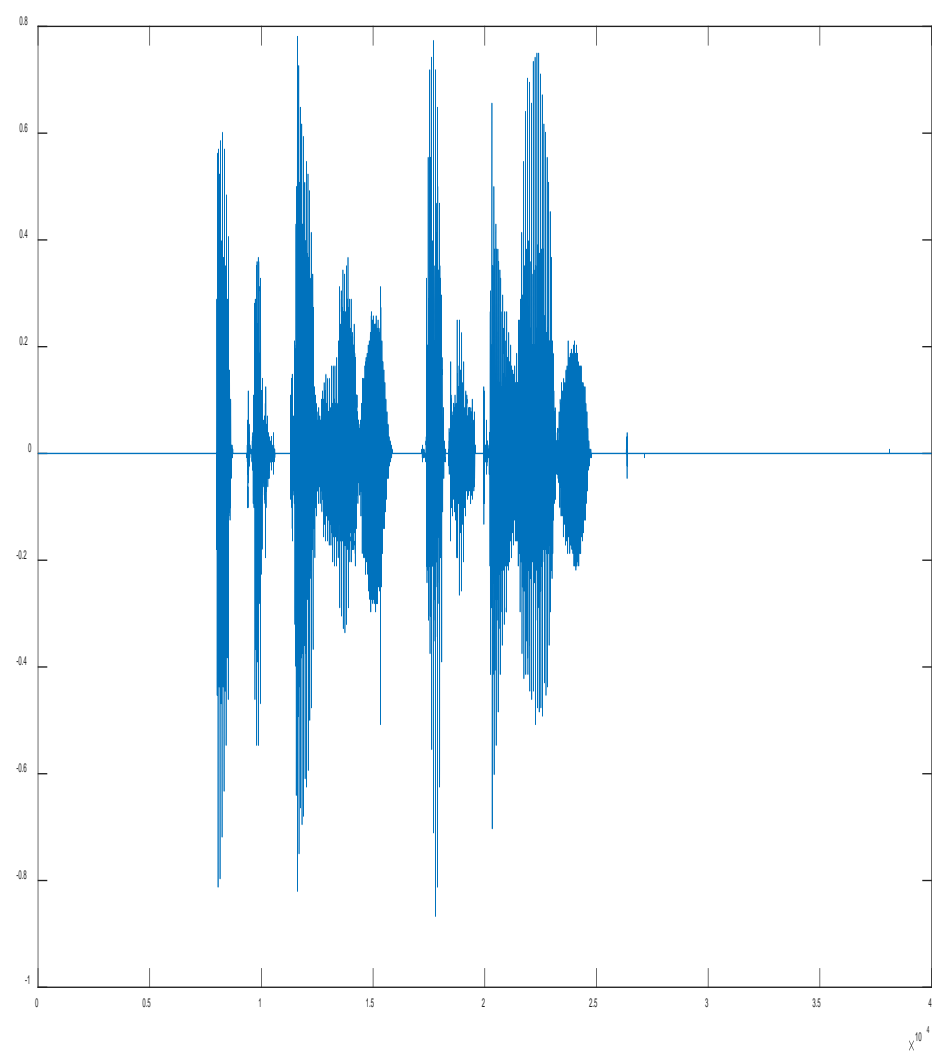

$\mathrm{X}$-axis $\rightarrow$ time, $\mathrm{Y}$-axis $\rightarrow$ amplitude

Figure 8. First experimental speech signal of third person. 


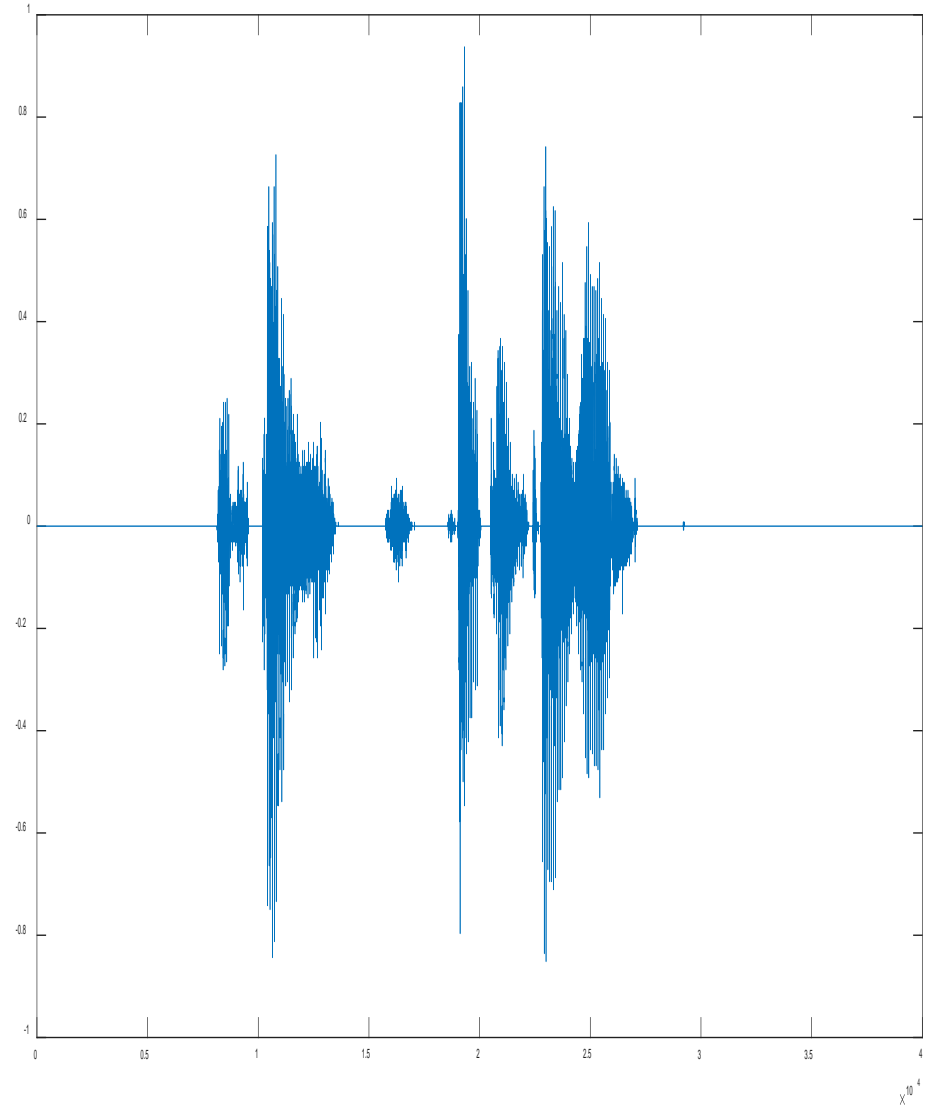

$\mathrm{X}$-axis $\rightarrow$ time, $\mathrm{Y}$-axis $\rightarrow$ amplitude

Figure 9. Second experimental speech signal of third person.

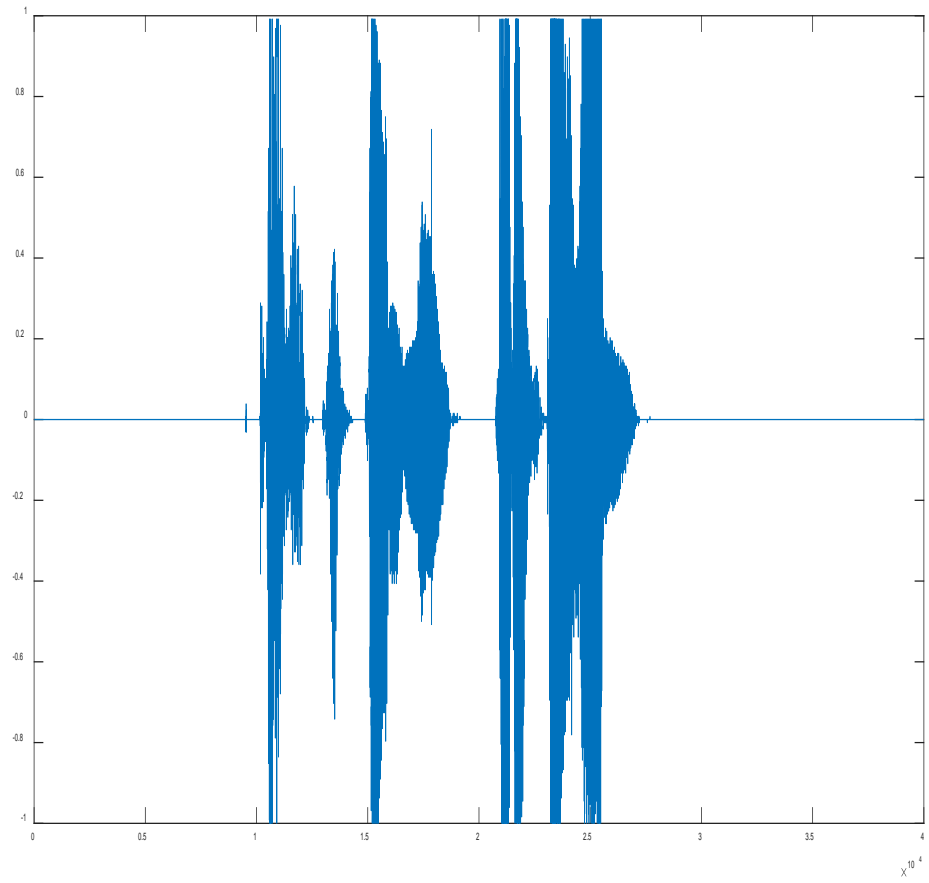

$\mathrm{X}$-axis $\rightarrow$ time, $\mathrm{Y}$-axis $\rightarrow$ amplitude

Figure 10. Third experimental speech signal of third person. 


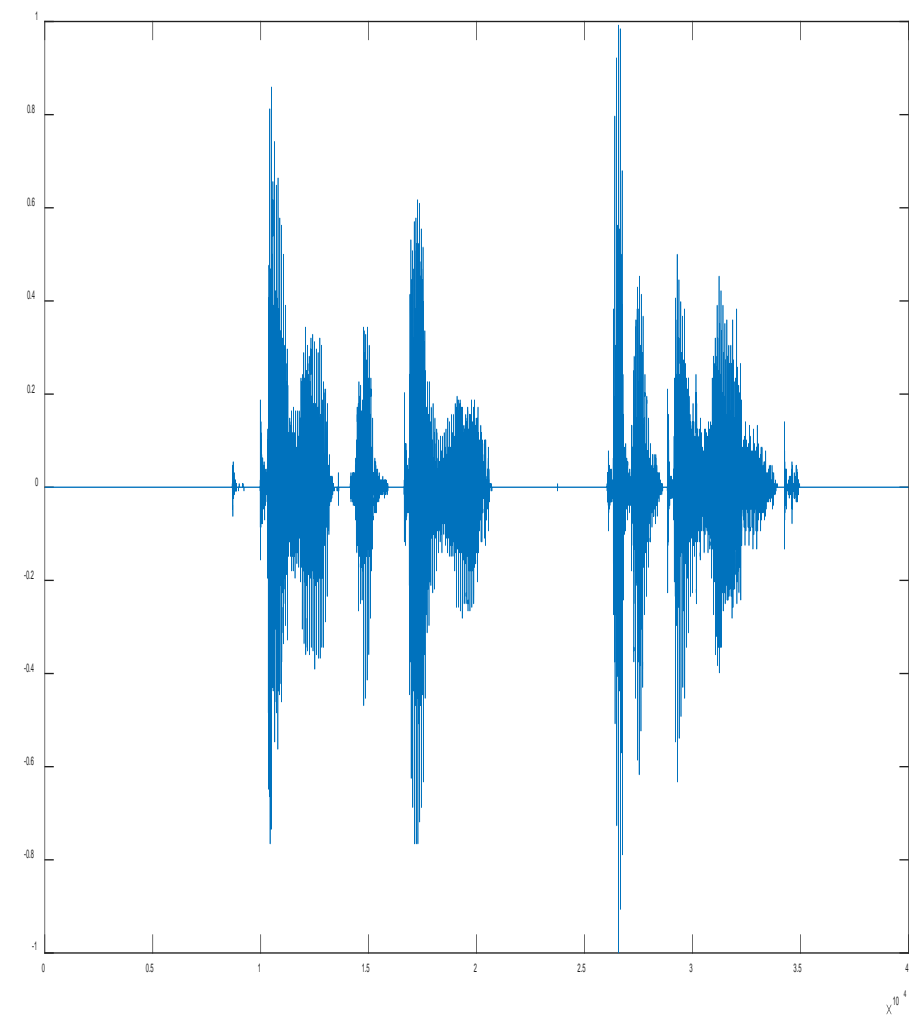

$\mathrm{X}$-axis $\rightarrow$ time, $\mathrm{Y}$-axis $\rightarrow$ amplitude

Figure 11. First experimental speech signal of forth person.

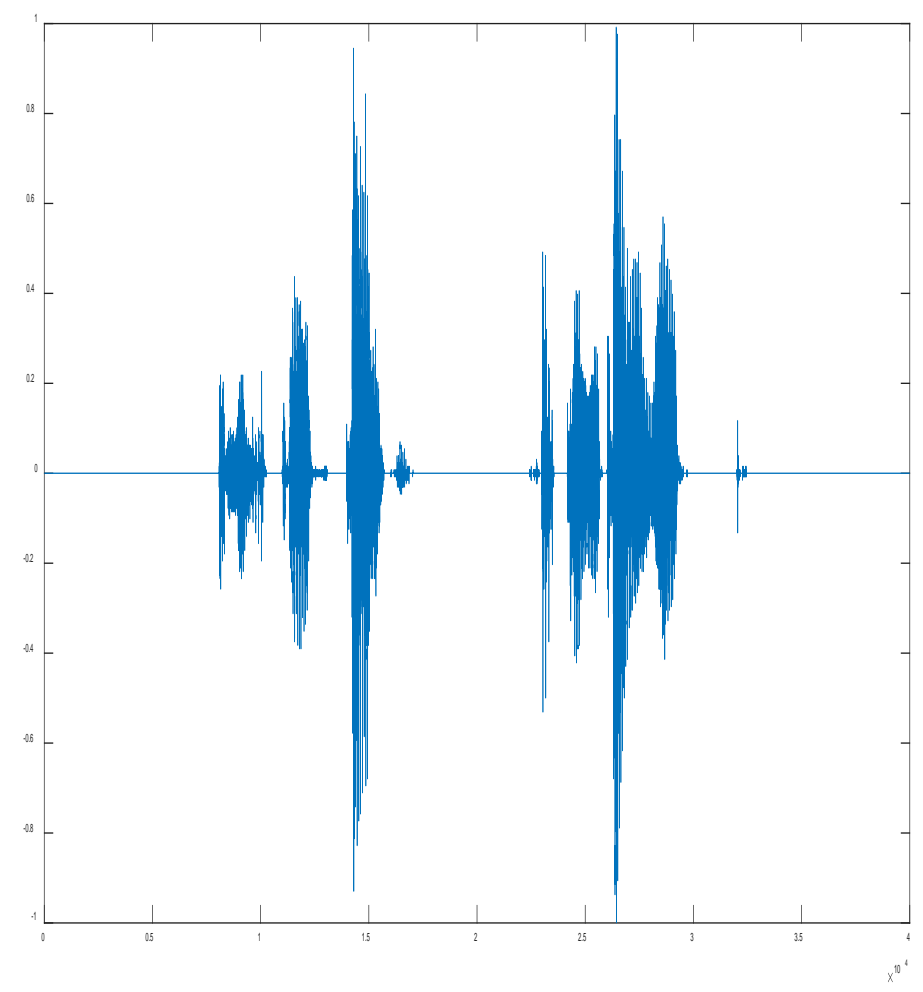

$\mathrm{X}$-axis $\rightarrow$ time, $\mathrm{Y}$-axis $\rightarrow$ amplitude

Figure 12. Second experimental speech signal of forth person. 


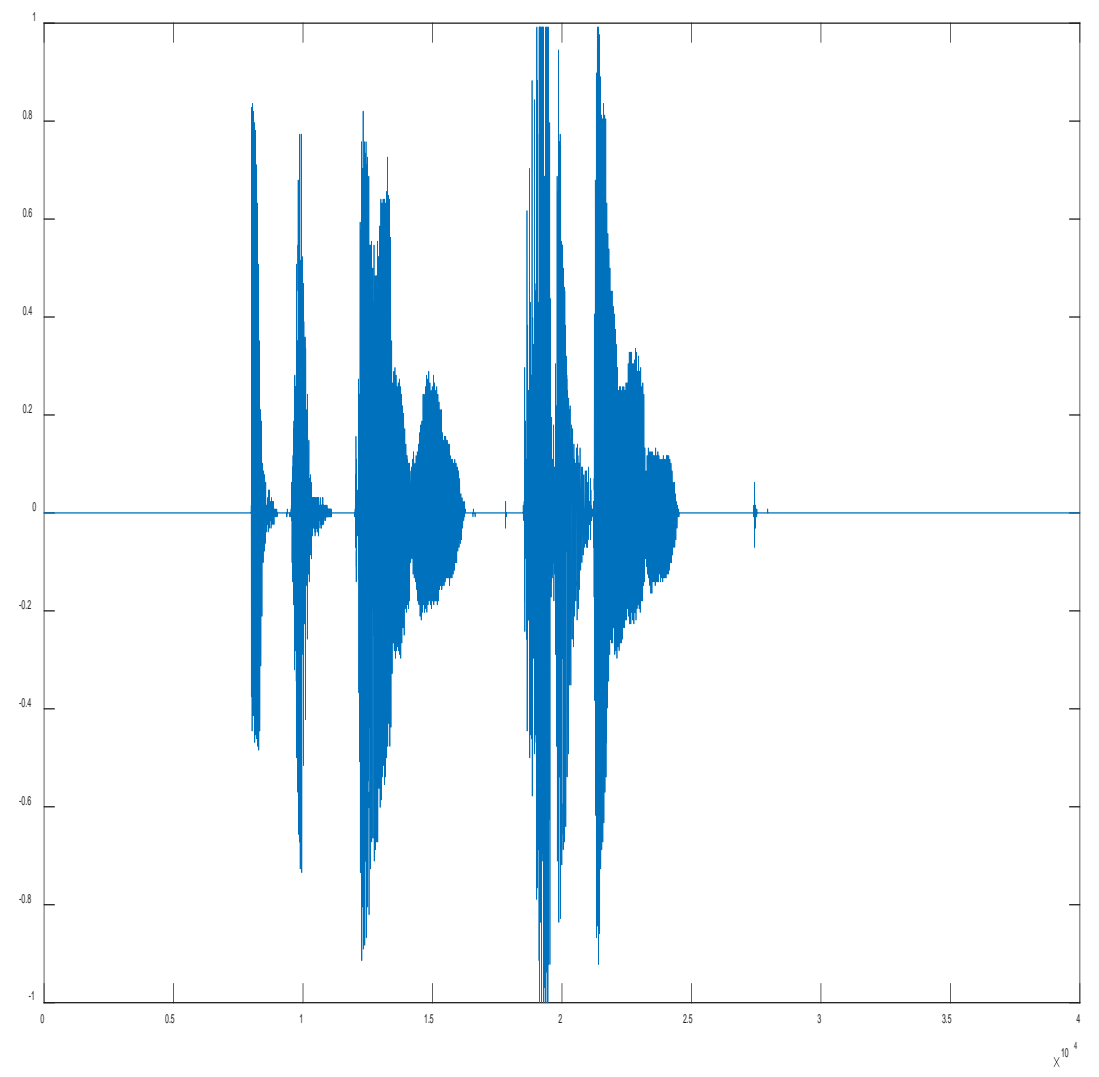

$\mathrm{X}$-axis $\rightarrow$ time, $\mathrm{Y}$-axis $\rightarrow$ amplitude

Figure 13. Third experimental speech signal of forth person.

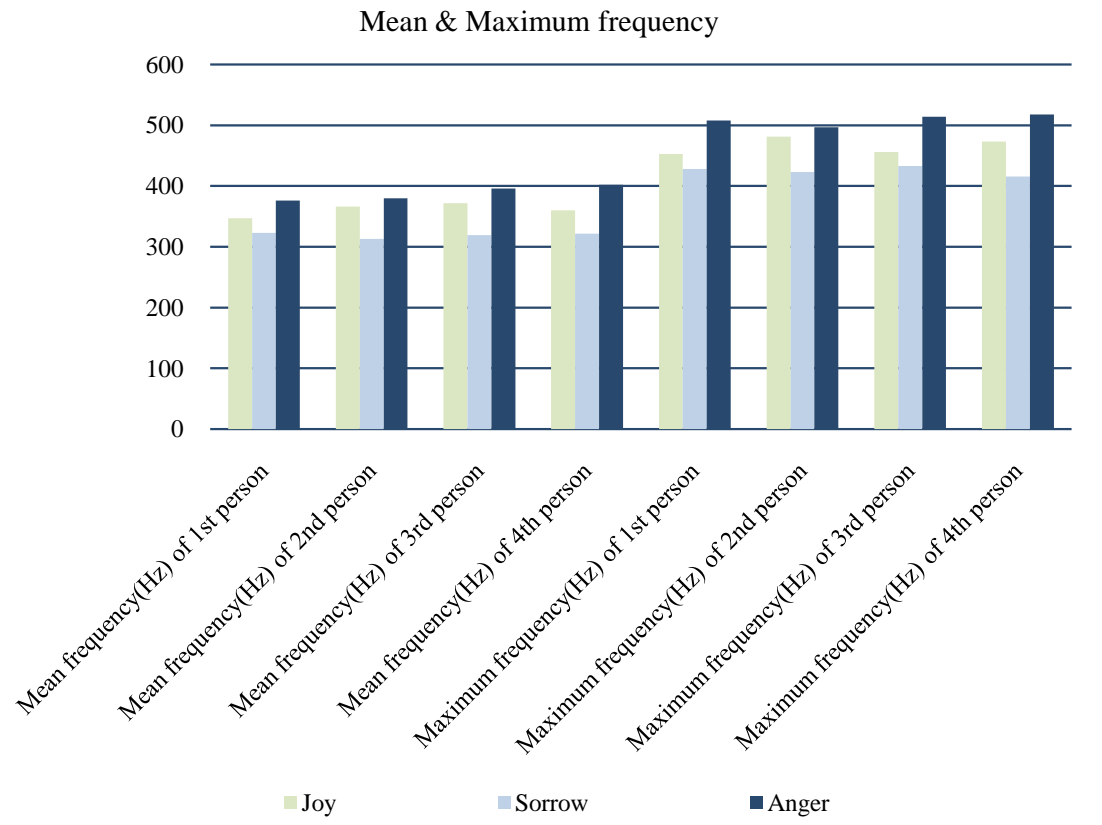

Figure 14. Comparison chart for frequency. 


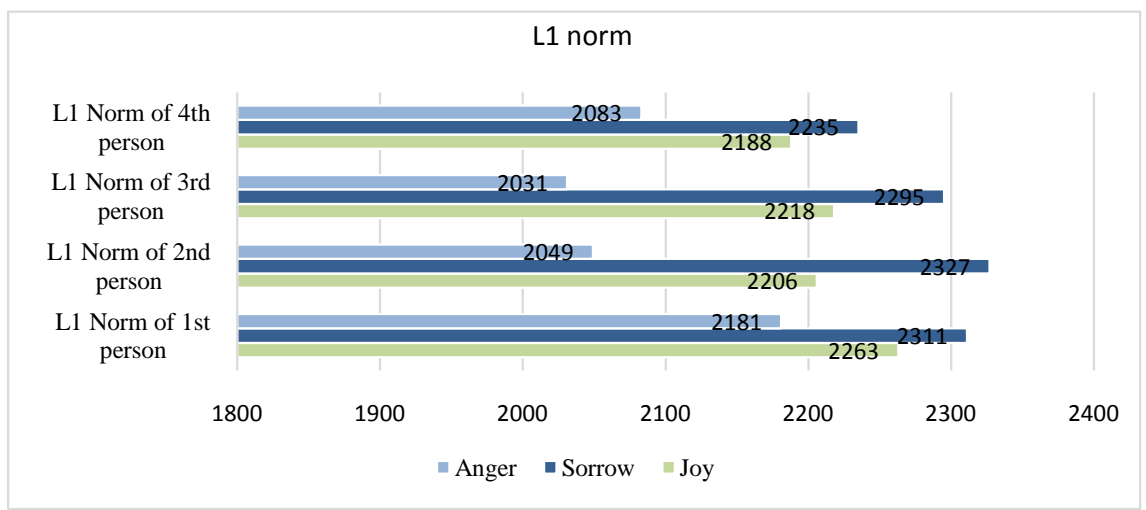

Figure 15. Comparison chart for $L_{1}$ norm.

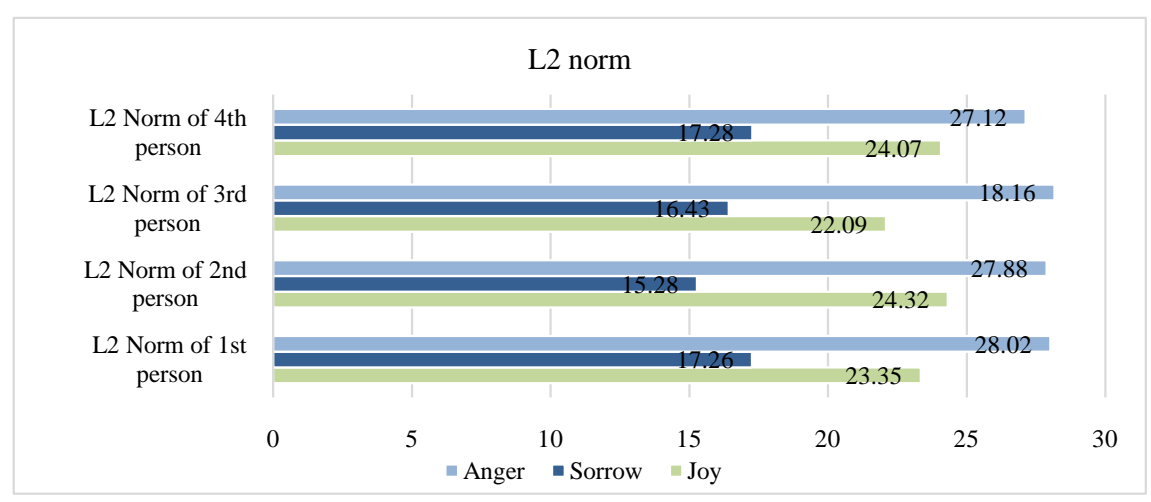

Figure 16. Comparison chart for $L_{2}$ norm.

Table 1. Data chart for first person.

\begin{tabular}{ccccc}
\hline $1^{\text {st }}$ person & Mean frequency $(\mathrm{Hz})$ & Maximum frequency $(\mathrm{Hz})$ & $L_{1}$ Norm & $L_{2}$ Norm \\
\hline Joy & 347 & 453 & 2263 & 23.35 \\
Sorrow & 323 & 428 & 2311 & 17.26 \\
Anger & 376 & 508 & 2181 & 28.02 \\
\hline
\end{tabular}

Table 2. Data chart for second person.

\begin{tabular}{ccccc}
\hline $2^{\text {nd }}$ person & Mean frequency $(\mathrm{Hz})$ & Maximum frequency $(\mathrm{Hz})$ & $L_{1}$ Norm & $L_{2}$ Norm \\
\hline Joy & 366 & 481 & 2206 & 24.32 \\
Sorrow & 313 & 423 & 2327 & 15.28 \\
Anger & 380 & 497 & 2049 & 27.88 \\
\hline
\end{tabular}

Table 3. Data chart for third person.

\begin{tabular}{ccccc}
\hline $3^{\text {rd }}$ person & Mean frequency $(\mathrm{Hz})$ & Maximum frequency $(\mathrm{Hz})$ & $L_{1}$ Norm & $L_{2}$ Norm \\
\hline Joy & 372 & 456 & 2218 & 22.09 \\
Sorrow & 319 & 433 & 2295 & 16.43 \\
Anger & 396 & 514 & 2031 & 28.16 \\
\hline
\end{tabular}


Table 4. Data chart for fourth person.

\begin{tabular}{ccccc}
\hline $4^{\text {th }}$ person & Mean frequency $(\mathrm{Hz})$ & Maximum frequency $(\mathrm{Hz})$ & $L_{1}$ Norm & $L_{2}$ Norm \\
\hline Joy & 360 & 473 & 2188 & 24.07 \\
Sorrow & 322 & 416 & 2235 & 17.28 \\
Anger & 402 & 518 & 2083 & 27.12 \\
\hline
\end{tabular}

Table 5. Data table for all frequency.

\begin{tabular}{cccc}
\hline \multirow{2}{*}{$\begin{array}{c}\text { Frequency } \\
\downarrow\end{array}$} & \multicolumn{3}{c}{ Different types of emotions of people } \\
\cline { 2 - 4 } & Joy & Sorrow & Anger \\
\hline & $347\left(1^{\text {st }}\right.$ person $)$ & $323\left(1^{\text {st }}\right.$ person $)$ & $376\left(1^{\text {st }}\right.$ person $)$ \\
Mean frequency (Hz) & $366\left(2^{\text {nd }}\right.$ person $)$ & $313\left(2^{\text {nd }}\right.$ person $)$ & $380\left(2^{\text {nd }}\right.$ person $)$ \\
& $372\left(3^{\text {rd }}\right.$ person $)$ & $319\left(3^{\text {rd }}\right.$ person $)$ & $396\left(3^{\text {rd }}\right.$ person $)$ \\
& $360\left(4^{\text {th }}\right.$ person $)$ & $322\left(4^{\text {th }}\right.$ person $)$ & $402\left(4^{\text {th }}\right.$ person $)$ \\
Maximum frequency & $481\left(2^{\text {nd }}\right.$ person $)$ & $423\left(2^{\text {nd }}\right.$ person $)$ & $497\left(2^{\text {nd }}\right.$ person $)$ \\
$(\mathrm{Hz})$ & $456\left(3^{\text {rd }}\right.$ person $)$ & $433\left(3^{\text {rd }}\right.$ person $)$ & $514\left(3^{\text {rd }}\right.$ person $)$ \\
& $473\left(4^{\text {th }}\right.$ person $)$ & $416\left(4^{\text {th }}\right.$ person $)$ & $518\left(4^{\text {th }}\right.$ person $)$ \\
\hline
\end{tabular}

Table 6. Data table for all $L_{p}$ norm.

\begin{tabular}{cccc}
\hline \multirow{2}{*}{$L_{p} \downarrow$} & \multicolumn{3}{c}{ Different types of emotions of people } \\
\cline { 2 - 4 } & Joy & Sorrow & Anger \\
\hline \multirow{2}{*}{$L_{1}$ Norm } & $2263\left(1^{\text {st }}\right.$ person $)$ & $2311\left(1^{\text {st }}\right.$ person $)$ & $2181\left(1^{\text {st }}\right.$ person $)$ \\
& $2206\left(2^{\text {nd }}\right.$ person $)$ & $2327\left(2^{\text {nd }}\right.$ person $)$ & $2049\left(2^{\text {nd }}\right.$ person $)$ \\
& $2218\left(3^{\text {rd }}\right.$ person $)$ & $2295\left(3^{\text {rd }}\right.$ person $)$ & $2031\left(3^{\text {rd }}\right.$ person $)$ \\
& $2188\left(4^{\text {th }}\right.$ person $)$ & $2235\left(4^{\text {th }}\right.$ person $)$ & $2083\left(4^{\text {th }}\right.$ person $)$ \\
& $23.35\left(1^{\text {st }}\right.$ person $)$ & $17.26\left(1^{\text {st }}\right.$ person $)$ & $28.02\left(1^{\text {st }}\right.$ person $)$ \\
& $24.32\left(2^{\text {nd }}\right.$ person $)$ & $15.28\left(2^{\text {nd }}\right.$ person $)$ & $27.88\left(2^{\text {nd }}\right.$ person $)$ \\
& $22.09\left(3^{\text {rd }}\right.$ person $)$ & $16.43\left(3^{\text {rd }}\right.$ person $)$ & $28.16\left(3^{\text {rd }}\right.$ person $)$ \\
& $24.07\left(4^{\text {th }}\right.$ person $)$ & $17.28\left(4^{\text {th }}\right.$ person $)$ & $27.12\left(4^{\text {th }}\right.$ person $)$ \\
\hline
\end{tabular}

\section{Conclusion}

In the above discussion, we have discussed many issues of voice signal. Our aim was to give a complete aspect of how voice signals behave in different ways of emotion of people. By processing the voice signal through wavelet analysis, we have seen that the signal changes its structure in case of three different moods (joy, sorrow and anger) and give characteristic values of mean frequency, maximum frequency, $L_{1}$ norm and $L_{2}$ norm. In this way by making a relationship among these characteristic calculations, we can easily determine the emotion of voice signal. These results not only help to determine the emotion but also they 
give important information about speakers. Emotion detection through voice signal analysis plays an important role in machine learning, robotics, artificial intelligence, data mining, voice biometric, intelligence division, forensic department etc. With the help of voice biometric, forensic and voice identification process, our intelligence department will be able to identify many criminals, as a result our cybercrime will greatly reduce. Now a day's voice automation is very popular and widely used medium. Already, many things are being done through voice commands and in the near future, this sector will be spread. Voice security is very popular among the many trusted security media. Therefore, in the present world, emotion detection, voice identification, specification and speaker recognition are a very important task. In this paper, we have generated codes with the help of MATLAB Programming and recorded our sound by regular headphone so some noise may be mixed with the original voice. We will try to improve this issue in the future.

\section{Conflicts of Interest}

The authors declare no conflicts of interest regarding the publication of this paper.

\section{References}

[1] Gabor, D. (1946) Theory of Communication. Journal of Institute of Electrical and Electronics Engineers, 93, 429-457. https://doi.org/10.1049/ji-3-2.1946.0076

[2] Littlewood, J.E. and Paley, R.E.A.C. (1931) Theorems on Fourier Series and Power Series. Journal of the London Mathematical Society, 6, 230-233.

https://doi.org/10.1112/jlms/s1-6.3.230

[3] Rioul, O. and Vetterli, M. (1991) Wavelets and Signal Processing. Institute of Electrical and Electronics Engineers of Signal Processing Magazine, 8, 14-38. https://doi.org/10.1109/79.91217

[4] Badsha, M.F., Islam, M.R. and Bulbul, M.F. (2018) Object Detection by Point Feature Matching Using Matlab. Advances in Image and Video Processing, 6, 22-29.

[5] Favero, R.F. (1994) Compound Wavelets: Wavelets for Speech Recognition. Institute of Electrical and Electronics Engineers Communications Letters, 17, 600-603. https://doi.org/10.1109/TFSA.1994.467280

[6] Meyer, Y. (1993) Wavelets, Algorithms and Applications. Society for Industrial and Applied Mathematics, Philadelphia, PA.

[7] Agbinya, J.I. (1996) Discrete Wavelet Transform Techniques in Speech Proccesing. International Technical Conference of Institute of Electrical and Electronics Engineers, 2, 514-519.

[8] Pasti, L., Walczak, B., Massart, D.L. and Reschiglian, P. (1999) Optimization of Signal Denoising in Discrete Wavelet Transform. Chemometrics and Intelligent Labratiory Systems, 48, 21-34. https://doi.org/10.1016/S0169-7439(99)00002-7

[9] Boll, S.F. (1979) Suppression of Acoustic Noise in Speech Using Spectral Subtractionv. IEEE Transactions on Acoustics, Speech, and Signal Proceedings, 27, 56-72. https://doi.org/10.1109/TASSP.1979.1163209

[10] Chen, J.-F. and Ser, W. (2000) Speech Detection Using Microphone Array. Elec- 
tronic Letters, 36, 181-182. https://doi.org/10.1049/el:20000140

[11] Rabiner, L. and Juang, B. (1993) Fundamentals of Speech Recognition. Prentice Hall PTR, Englewood Cliffs, NJ. 